\title{
Undergraduate-Led Survey Class to Improve CS Education for New Students
}

\author{
Nathan Zhang* \\ Stanford University \\ stanfurd@stanford.edu
}

\author{
Jacky Liang* \\ Carnegie Mellon University \\ jackyliang@cmu.edu
}

\author{
Amanda Tomlinson* \\ Texas Instruments \\ amandatomlinson@berkeley.edu
}

\author{
Frank Boensch \\ University of California, Berkeley \\ fboensch@berkeley.edu
}

\author{
Anant Sahai \\ University of California, Berkeley \\ sahai@eecs.berkeley.edu
}

\begin{abstract}
Many first-year undergraduate students do not have sufficient breadth of technical knowledge about subjects in Electrical Engineering (EE) and Computer Science (CS) to make informed choices toward their education. By the time students are exposed to subjects they may be interested in, the cost of switching areas of focus may be too high. With undergraduate enrollment in CS more than doubling in the past decade, many institutions lack adequate staff and infrastructure to address students' needs. To help newly enrolled students make better decisions with limited departmental resources, we present a first-semester, low-overhead survey course that covers a wide variety of topics. The class has been offered for five consecutive semesters by upper-class undergraduate volunteers with minimal faculty involvement. We report the format, content, and student feedback for the course. Our results suggest that such a class can provide new students with valuable guidance and better prepare them for an education in CS and EE.
\end{abstract}

\section{CCS CONCEPTS}

- Social and professional topics $\rightarrow$ Computing education programs.

\section{KEYWORDS}

CS1/2, Experience Report, Managing Enrollment Growth, Undergraduate Instruction, Undergraduate Studies

\section{ACM Reference Format:}

Nathan Zhang, Jacky Liang, Amanda Tomlinson, Frank Boensch, and Anant Sahai. 2020. Undergraduate-Led Survey Class to Improve CS Education for New Students. In The 51st ACM Technical Symposium on Computer Science Education (SIGCSE '20), March 11-14, 2020, Portland, OR, USA. ACM, New York, NY, USA, 7 pages. https://doi.org/10.1145/3328778.3366897

\section{INTRODUCTION}

Undergraduate enrollment in computer science-related majors at many institutions has grown in recent years, with more than $60 \%$ of

${ }^{*}$ Work done while affiliated with the University of California Berkeley

Permission to make digital or hard copies of part or all of this work for personal or classroom use is granted without fee provided that copies are not made or distributed for profit or commercial advantage and that copies bear this notice and the full citation on the first page. Copyrights for third-party components of this work must be honored.

For all other uses, contact the owner/author(s).

SIGCSE '20, March 11-14, 2020, Portland, OR, USA

(C) 2020 Copyright held by the owner/author(s).

ACM ISBN 978-1-4503-6793-6/20/03.

https://doi.org/10.1145/3328778.3366897 institutions reporting at least a $100 \%$ increase in computer science students ${ }^{1}$. The Computing Research Association notes that "While academic units are taking a range of actions to handle the increased enrollment, percentage increases in tenure-track faculty are about 1/10-th of the increase in the number of majors."

Lack of teaching staff and overcrowded classes can pressure students with little background in Electrical Engineering (EE) and Computer Science (CS) ${ }^{2}$ to follow the most common tracks in the major, instead of taking more time to explore. Table 1 contains CS enrollment data for University of California at Berkeley (UC Berkeley) ${ }^{3}$ and Los Angeles (UCLA) ${ }^{4}$, and University of Maryland at College Park (UMD) ${ }^{5}$. In these schools with large CS departments, there are significant gaps between areas of courses that are highly and sparsely enrolled. While this discrepancy may not be directly indicative of an issue, interactions with undergraduates at our institution indicate that many students do not consider the full spectrum of courses. We leave the evaluation of the impact of our work as future work.

\subsection{Problem Statement and Approach}

Due to a lack of sufficient advice and prior knowledge, many first year students choose their classes not based on educational or career goals, but on course enjoyment or the "default" curriculum [12]. In this work, we focus on large academic programs, such as those found at heavily-enrolled public schools. At these institutions, the growth of the majors have exceeded the academic support capacity, with advising wait times reaching multiple weeks ${ }^{6}$. The reason why fields like circuits, device physics, architecture, and theoretical computer science should be studied may not become apparent without prior exposure. The issue is exacerbated by insufficient educational resources that create institutional pressures, which can lead to students taking popular courses without exploring alternatives.

Our proposed approach is to have undergraduates run a firstsemester, low-overhead survey course that explores most topics in

\footnotetext{
${ }^{1}$ cra.org/data/generation-cs/phenomenal-growth-cs-majors-since-2006/

${ }^{2}$ Many schools offer majors in Computer Science (CS) and Electrical Engineering (EE). While some offer a joint major (EECS), many also offer majors that concentrate toward one or the other, e.g. Computer Science Engineering (CSE), Electrical Computer Engineering (ECE), and Computer Engineering (CE). In this paper, we use the term "EE/CS" to refer to the general field of study that encompasses all the above majors, as that is what our course covered.

${ }^{3}$ berkeleytime.com

${ }^{4}$ sa.ucla.edu/ro/public/soc

${ }^{5}$ app.testudo.umd.edu/soc/201901

${ }^{6}$ https://berkeleyeecs.youcanbook.me/service/jsps/cal.jsp?cal=8e8a1f24-16fd-43e0$8 \mathrm{~b} 45-\mathrm{c} 99 \mathrm{f} 642 \mathrm{ac} 0 \mathrm{ab}$
} 


\begin{tabular}{c|c|c|c|c|c|c|c|c} 
School & Algorithms & AI/ML & Operating Systems/Compilers & Other Systems & Theory & Circuits & Signals & Arch. \\
\hline UC Berkeley & 940 & 1761 & 548 & 1063 & 113 & 166 & 205 & 148 \\
UCLA & 519 & 240 & 466 & 432 & 145 & 335 & 230 & 78 \\
UMD & 1070 & 522 & 916 & 527 & 499 & 224 & 135 & 310
\end{tabular}

Table 1: Enrollment counts of different upper-division level course areas during the Spring 2019 term. Other Systems includes databases, networks, and other typically non-mandatory courses. We have omitted applications-oriented courses such as graphics or software engineering.

$\mathrm{EE} / \mathrm{CS}$ to enable students to make more informed decisions about their curriculum and career. We believe that more experienced undergraduates can be effective teachers and mentors to new students.

By the end of the course, students should be able to understand at a high level how courses offered by the department interact and form coherent areas of focus. Additionally, we hope to provide enough interaction with a diverse set of areas so students can understand how less popular courses can be valuable.

In order to recruit undergraduate instructors for this course, we worked with one of our school's honor societies that represents students in EE/CS. Many of the students in the honor society have experience working as teaching or research assistants. All undergraduate instructors were volunteers and chose the course topics that they were most passionate about. Support from the honor society also helps to keep the class sustainable as the staff graduate.

The learning goals for the teaching staff are more abstract but are primarily aimed at benefits similar to interteaching [23, 24, 26] and increased exposure to faculty, graduate students, and research.

\subsection{Institutional Context}

In order to address the massive increase in demand for teaching staff, many courses at our institution, UC Berkeley, have begun using undergraduate students as teaching assistants, many of whom both provide course content as well as lead recitations. Other schools such as the University of Maryland at College Park and Massachusetts Institute of Technology (MIT) now have sizable undergraduate teaching staff. At UC Berkeley, the majority of computer science teaching assistants are undergraduate teaching assistants (UTAs) instead of graduate teaching assistants (GTAs).

Undergraduate facilitated classes are not without precedent as seen with the DeCal Program ${ }^{7}$ at UC Berkeley, Student Initiated Courses ${ }^{8}$ at Stanford University, and DemTex ${ }^{9}$ at University of Texas at Austin. These courses have typically addressed topics outside of the typical purview of college education and are taken for enrichment or curiosity.

Like at many other institutions, undergraduates are widely employed in a variety of instructional roles at our campus, ranging from assisting during laboratory sections to acting as the primary instructors during summer sessions for lower division courses. A majority of TAs are UTAs and are responsible for both course content development as well as leading discussion sections. Our institution provides training courses for both laboratory and teaching assistants that are mandatory for all first-time UTAs and GTAs. Additionally, many UTAs also conduct research alongside graduate students or faculty, giving them hands-on experience in cuttingedge technology. This experience proved to be very useful when designing lectures and lab exercises. Additionally, as later presented

\footnotetext{
$\overline{{ }^{7} \text { decal.berkeley.edu }}$

${ }^{8}$ registrar.stanford.edu/staff/student-initiated-courses-sics

${ }^{9}$ ugs.utexas.edu/news/2011/summer/demtex
}

in table 4, undergraduates prefer UTAs over GTAs when selecting for clarity, helpfulness, availability, approachability, and dedication.

\subsection{Overview of Our Experience}

In this paper, we present our experience with a course created and run by a group of undergraduates under faculty supervision. This course targets first-semester freshman and transfer students with minimal prior experience during their first year in attendance in order to provide an introduction into the sub-fields of EE/CS. Students were given one unit (1/16th of a typical semester load) of non-letter-graded course credit for a two hour session each week along with homework and a final project.

\section{RELATED WORKS}

Past research indicate that newly-enrolled CS undergraduate students with little programming experience are more likely to drop out of the first CS course [15] and that prior exposure remains an important predictor of persistence even beyond the first two CS courses [14]. Additionally, a study of undergraduates at Carnegie Mellon University found that students who declare majors as early as their second semester have the highest likelihood of switching majors later as they discover how their original choices do not align with their interests [6].

The high cost of switching areas of focus disproportionately impacts those who are undecided in their paths. Prior work by Lehman et. al. indicates that women in CS tend to be more likely to be undecided in their career paths than men [17]. Furthermore, according to a 2008 article in IEEE Spectrum, "While many areas within EE make clearly positive contributions to society, we don't market that aspect of our field well enough" [11], which suggests that a lack of prior knowledge impedes proper focus selection.

Many works have investigated potential solutions to improve retention and success in CS and STEM classes for new students with less technical background than their peers [16]. One approach is to design teaching methodologies and courses that specifically target these students. One work found that the diverse technical background of students necessitate different teaching methods to ensure students' engagement and retention [18]. Another studied the effectiveness of a CS0 course, which is taught to under-prepared students before the introductory-level CS1 course; taking the CS0 course helped improve students' success in CS1 [5].

Some studies also detail schools' efforts to improve the retention rate of at-risk students, often defined as those who are earning insufficient grades in introductory classes and who are not on track for graduation. One school offered a summer bridge program to help at-risk CS students be more prepared for introductory-level courses, and almost all attendees of the program were on-track for graduation in the semesters that followed [13]. Helping at-risk engineering students through advising, academic workshops, and scholarships has also been shown to increase graduation rate [2]. However, many issues facing at-risk CS students, such as paying 
tuition and maintaining student visa status [10], are non-academic, and this paper does not aim to address those challenges.

In this work, we propose a first-year survey class led by experienced undergraduates as a potential solution to improve CS education for new and under-prepared students. Our emphasis on undergraduate-led instruction is motivated by its low cost and administrative overhead, as this doesn't require a full-time teaching faculty as well as numerous studies that show the merits of peer-led instruction. One well-studied and promising peer-teaching method is interteaching, where students work with each other through a pre-defined lesson plan, answering each other's questions, and the instructor provides little to no lecture, only intervening when necessary [23, 24, 26]. Interteaching, however, does not satisfy our goal of having new students interact with older undergraduates who can use their experience in the school and program to provide valuable advice and mentorship.

Instead, the role of undergraduate instructors of our proposed course can be seen as an extension of UTAs which many studies have shown to be promising [9]. Numerous studies found that when comparing classes taught by UTAs and GTAs, UTA-led instruction achieved comparable, and at times even better, student performance than GTA-led ones in science classes and labs [4, 21, 28]. Furthermore, surveying both students and TAs has shown that UTAs can provide more encouragement to students [21] and employ more engaging teaching styles than GTAs [27]. In addition to studies showing the benefits of teaching for the UTAs for solidifying learning and improving communication skills [7, 8, 22, 25], these results suggest there is potential and merit in classes taught by undergraduates. Notably, undergraduate students have led seminar classes at Pennsylvania State University [3] and Stanford University [19], and the DeCal program at UC Berkeley finds its roots to experimental classes that began as early as 1967 [1]. Since 2017, undergraduates have been employed as primary instructors for the introductory CS61 series during summer sessions at UC Berkeley. ${ }^{10}$

\section{CURRICULUM}

\subsection{Overview}

Table 2 summarizes the curriculum of our course.

We motivate the discussion of the EE/CS stack by posing the question of how watching a YouTube video works, which was chosen for approachability. Each class is a layer in the EE/CS stack, and we start from software and proceed into hardware. Not all of our classes are immediately applicable to YouTube, as we prioritize covering the breadth of subjects in EE/CS. We note that many other subjects, such as music streaming and mobile applications, can be used to motivate this approach as well.

There is a total of 11 classes, and each class consists of a mixture of lecture and lab in a two-hour format, with a ten-minute break in the middle. We design the content of each class with the goal of giving students enough understanding of the topic to conduct a productive conversation about it with a peer.

The class is organized by an EE/CS honor society which consists of the top third of seniors and top quarter of junior students ranked by GPA. Instructors were invited to teach one or two classes,

\footnotetext{
${ }^{10} \mathrm{http}: / /$ classes.berkeley.edu
}

sometimes grouped as co-instructors. We selected undergraduate students who have prior teaching experience and who are wellversed in the week's topic, evaluating knowledge based on research experience in the field.

We chose the subjects based on upper division course offerings, research areas at our institution, and availability of volunteer instructors; through the honors society we were able to find a balanced set of instructors that covered a large range of subjects.

Because our course is aimed toward students with little to no EE/CS background, we controlled for the technical experience and class size through an online application process. The application asked questions about academic standing and number of years of prior EE/CS experience. We turned away students with more than two semesters of coursework in the major, and we admitted all first-semester regular and transfer students who applied.

\subsection{Class Preparation}

For the first offering of the class, we prepared the lecture and lab content continuously throughout the semester, and these material were reused in latter offerings. During the semester we adhere to the following schedule to ensure classes are adequately prepared in advance.

4 weeks prior: finalize the instructor(s) for the class and work with them to brainstorm goals and content.

3 weeks prior: review lecture and lab outlines and begin preparing any needed materials for the labs.

2 weeks prior: dry-run lecture and labs for internal review and feedback.

1 week prior: make final revisions and ensure hardware or software lab materials are prepared.

\subsection{Content}

The classes are ordered from higher to lower levels of abstraction in the EE/CS "stack" - starting from the technology behind web pages, servers, and videos and going down to the physics of transistors. The lecture portion of the course introduces the material of the week, relevant research opportunities on campus, and how the technologies introduced are used in industry. This contextual information helps students construct a more useful perspective on both the academic and industrial states of the field. Depending on the content of the class, we created software and/or hardware labs. Software labs require minimal coding and hardware labs construct simple circuits, although sometimes simulation software is used in place of real circuits. All materials presented in class, including slides, source code, lab instructions, and a recorded video of the lecture, are posted online after the class for students to review.

\subsection{Activities}

In addition to the regular course material, we also organized activities to further expose the students to various areas. During Week 9, we coordinated a trip to a museum themed around technology and computing with the goal of providing historical and cultural contexts for EE/CS. The week after, we conducted a tour of a robotics research lab where a few graduate and undergraduate researchers helped give demonstrations of the lab's current projects. The researchers also answered students' questions about doing research both as an undergraduate and as a graduate student. 
Table 2: Curriculum Summary

\begin{tabular}{|c|c|c|c|}
\hline Week & Topic & Lecture & Labs \\
\hline 1 & Introduction & Introduction. Ice breaker. Talk by supervising faculty. & $\mathrm{n} / \mathrm{a}$ \\
\hline 2 & $\begin{array}{l}\text { What is a YouTube } \\
\text { Video }\end{array}$ & $\begin{array}{l}\text { Overview of video and audio data encoding, and how } \\
\text { they're sent over networks. }\end{array}$ & $\begin{array}{l}\text { Image and audio data with arrays and matrices. } \\
\text { Sound in both frequency and time domains. Do- } \\
\text { main name resolution and packet routing. }\end{array}$ \\
\hline 3 & $\begin{array}{l}\text { Machine Learning } \\
\text { and YouTube Rec- } \\
\text { ommender System }\end{array}$ & $\begin{array}{l}\text { Classification and regression using linear models, and } \\
\text { how YouTube uses both to recommend videos. }\end{array}$ & $\begin{array}{l}\text { Classification with hard-coded and perceptron } \\
\text { classifiers. Regression with linear and decision } \\
\text { tree models. }\end{array}$ \\
\hline 5 & $\begin{array}{l}\text { Applications and } \\
\text { the OS Interface }\end{array}$ & $\begin{array}{l}\text { Role of OS and languages in abstraction layers. Intro- } \\
\text { duction to distributed systems and compilers. }\end{array}$ & $\begin{array}{l}\text { Explore and modify simple in-house scripting lan- } \\
\text { guage and interpreter. Explore Unix filesystem. }\end{array}$ \\
\hline 6 & $\begin{array}{l}\text { How to Build a } \\
\text { Computer }\end{array}$ & $\begin{array}{l}\text { History of computers. Computer architecture. Logic, } \\
\text { binary arithmetic, ALU, CPU, and instruction sets. }\end{array}$ & $\begin{array}{l}\text { Explore constructing simple logical circuits with } \\
\text { Logisim. }\end{array}$ \\
\hline 9 & $\begin{array}{l}\text { Analog and Digital } \\
\text { Circuits }\end{array}$ & $\begin{array}{l}\text { History of transistors in digital and analog circuits. How } \\
\text { transistors are used in logic gates. }\end{array}$ & $\begin{array}{l}\text { Inspect inverter waveforms with Spice. Build an } \\
\text { inverter and other simple logic gates. }\end{array}$ \\
\hline 10 & $\begin{array}{l}\text { Controls, AI, and } \\
\text { Robotics }\end{array}$ & $\begin{array}{l}\text { Overview of signals and systems. Modeling with con- } \\
\text { troller and plant, and how they relate to AI and robotics. }\end{array}$ & $\begin{array}{l}\text { Implement LP filter on microcontroller to simulate } \\
\text { auto-brightness with photoresistor and LED. }\end{array}$ \\
\hline 11 & $\begin{array}{l}\text { Ethics in EE/CS and } \\
\text { Conclusion }\end{array}$ & $\begin{array}{l}\text { Discussion about ethical implications of technology and } \\
\text { the role of engineers. Conclusion of course and survey. }\end{array}$ & $\mathrm{n} / \mathrm{a}$ \\
\hline
\end{tabular}

\subsection{Assignments and Grading}

To encourage students to engage with the material during class and to reinforce what they have learned, we ask students to write a weekly report. These assignments are summaries of a related application of the materials covered that week found either in industry or in research, and help students learn more about each field. Additionally, the reports are also posted on Piazza, an educational forum website, so students can read other student's reports. We also assign a final project in which students design a lab on a topic of their choice. For this project, students need to clearly state what interesting or unintuitive idea the lab is trying to illustrate and to describe the concrete steps of this lab. Students don't have to necessarily perform the lab, as the goal of the final project is to encourage them to look deeper into a field they're interested in; through this process the students learn how and where to acquire technical knowledge outside of schoolwork.

A student's final grade is comprised of attendance and weekly assignments, and the final project is mandatory. Weekly attendance and report count as 1 point each, and while students can miss lectures and the weekly assignments, 17 out of 20 possible points must be earned in order to receive a passing grade. As noted previously, the course is offered for a single unit (1/16 of a semester load) with pass/fail grading.

\section{DISCUSSION}

\subsection{Feedback and analysis}

After each class, we collected a feedback survey which used anonymous 5-point Likert scale and open answer questions to gauge what students thought about the class, how this class helped them, and what areas can be improved. We collected data over the three iterations of the course. The overall response was positive, and a summary of selected questions is given in Table 3 .

Our main goals with the class were to help students gain a holistic view of topics in EE/CS and help them choose their classes with greater confidence. A majority of students agreed that the class did help them get a better understanding of topics in EE/CS, with a strong majority agreeing that the integrated lecture and lab was an effective teaching method for the material presented. However, students also agreed that they would prefer more of the "hands-on" activities and less lecture. Many students agree that the class had the "just-right" level of difficulty. This was important for us as we wish to give students sufficient technical depth to allow them to participate in meaningful conversations and help them learn more on their own, but not overwhelm them as most of the students have little prior technical background. A majority of students said that they would be more likely and/or confident to apply for research and internships after taking the class.

Another metric that we used to evaluate the class was if students felt it exposed them to less popular courses. When asked about plans for their next semester's classes, several students responded that they would be taking more electrical engineering and circuits classes, which are less popular at our institution. Students responded that the class "inspired me to do more circuit and ee based topics," and "I want to take more EE classes. The course was a good place to talk to people who've already taken upper div classes in the major." Students also felt that the class helped them realize 


\begin{tabular}{|c|c|c|c|c|c|c|}
\hline & Question & 1 & 2 & 3 & 4 & 5 \\
\hline 1 & This course helped you gain a more holistic view of topics in EE/CS. & 0 & 0 & 4 & 16 & 31 \\
\hline 2 & You feel comfortable talking to a friend about most of the layers in the EE/CS Stack & 0 & 3 & 9 & 22 & 17 \\
\hline 3 & This class has helped or will help you in choosing what future classes to take. & 0 & 2 & 6 & 25 & 18 \\
\hline 4 & You are more likely and/or confident to apply for undergrad research after taking this course. & 0 & 5 & 7 & 23 & 16 \\
\hline 5 & You are more likely and/or confident to apply for internships after taking this course. & 0 & 4 & 13 & 19 & 15 \\
\hline 6 & The teaching style (lecture + lab) was effective for learning the materials covered. & 0 & 2 & 10 & 16 & 23 \\
\hline 7 & You'd prefer more discussions and peer activities during class. & 1 & 5 & 17 & 16 & 12 \\
\hline 8 & You'd prefer more labs and hands-on labs during class. & 0 & 2 & 18 & 13 & 18 \\
\hline 9 & If applicable, the robotics lab tour made you more likely to apply for undergrad research. & 0 & 3 & 2 & 10 & 18 \\
\hline 10 & You're more likely to think about the ethical implications of your work in EE/CS after the ethics class. & 0 & 1 & 13 & 21 & 16 \\
\hline 11 & How difficult is this class if you were taking the first semester EE/CS classes concurrently? & 4 & 12 & 25 & 4 & 3 \\
\hline 12 & How likely is it for you to recommend this class to a first-year friend? & 0 & 2 & 7 & 14 & 28 \\
\hline 13 & Please give a score (higher the better) for this class taking everything into account. & 0 & 0 & 9 & 14 & 28 \\
\hline
\end{tabular}

Table 3: Feedback Survey Results. Questions 1-10 are 5-point Likert scale questions that asked students to rate each statement with labels of strongly disagree, disagree, neutral, agree, and strongly agree respectively in the range of 1-5. Question 11 had the labels of 1 to 5 ranging from too easy to too hard, and Question 12 ranged from very unlikely to very likely. Counts are summed across 3 of the 5 semesters where feedback were collected. Not all enrolled students responded to the feedback form.

\begin{tabular}{|c|c|c|c|c|c|c|c|}
\hline & Clarity & Knowledge & Helpfulness & Availability & Approachability & Dedication & Overall \\
\hline Strong prefer undergraduate & $13.65 \%$ & $7.12 \%$ & $12.88 \%$ & $14.23 \%$ & $19.42 \%$ & $14.23 \%$ & $10.96 \%$ \\
\hline Moderately prefer undergraduate & $14.86 \%$ & $8.27 \%$ & $20.19 \%$ & $20.96 \%$ & $24.62 \%$ & $18.27 \%$ & $17.12 \%$ \\
\hline Doesn't matter & $48.08 \%$ & $41.54 \%$ & $48.46 \%$ & $48.85 \%$ & $43.85 \%$ & $50.58 \%$ & $51.35 \%$ \\
\hline Moderately prefer graduate & $13.85 \%$ & $23.27 \%$ & $10.00 \%$ & $7.50 \%$ & $5.58 \%$ & $9.23 \%$ & $13.08 \%$ \\
\hline Strongly prefer graduate & $9.62 \%$ & $19.81 \%$ & $8.46 \%$ & $8.46 \%$ & $6.54 \%$ & $7.69 \%$ & $7.50 \%$ \\
\hline
\end{tabular}

Table 4: Department wide survey asked 520 students in 2017 to rate on a 5-point Likert scale if they preferred GTAs or UTAs for various categories. "Knowledge" and "Dedication" are based on students' perception. While students preferred GTAs for knowledge of the subject matter, they preferred UTAs for approachability and availability.

all the classes they could take, with one saying, "I would say I have a better understanding of what classes I'm interested in and what topics they cover," and another saying "I definitely think that this class helped me get a lot of exposure to the field."

\subsection{Lab Development}

Lab development required a significant portion of time during the first offering, as all sessions were completely new. For example, during the physics section, the instructor and an assistant spent upwards of $60 \%$ of the course development time designing a rough switch prototype based on a nanoelectromechanical switch [20]. Using this prototype, we were able to explain to students the overarching concepts behind building an electric switch as well as provide adequate flexibility so that students could create their own humanscale contraptions. In subsequent semesters most labs were reused or only changed slightly.

Since a major goal of the course was to provide students with an opportunity to explore the relevant areas, we designed our labs to be easily modifiable by students. Our compilers session provided students with a toy language which they could modify and execute, and our networking session had students simulate a simple routing network. By enabling students to interact with slivers of many different fields, the course allowed students to peer into a diverse set of potential areas of focus.

\subsection{Undergraduates as Instructors}

The choice to use undergraduate instructors was motivated by the belief that upper-class undergraduates are especially helpful for new students because they have gone through the undergraduate experience, and new students can immediately relate them. Upperclass undergraduates also understand the student perspective in taking classes and engaging in on-campus activities. They often shared their own experience in the program, provided advice for course selections, and offered mentorship to new students in ways that are more difficult to do for professors and graduate students.

Anecdotally, we found that the students in the class were very engaged with the undergraduate instructors, often staying after class to speak about the lecturer's field of research or the topic of the class. A popular topic of discussion for the students in the class was research opportunities and how undergraduate instructors joined their research projects. Students acknowledged that approaching professors for research projects was intimidating and were interested in a fellow undergraduate's advice regarding research.

In Table 4 we report a department-wide survey that asked students to rate on a 5-point Likert scale if they preferred an undergraduate or graduate instructor for various categories. Students preferred undergraduate over graduate instructors the most for their approachability and availability, while they preferred graduate instructors in perceived knowledge of the subject.

In the class feedback surveys, we asked students to give their thoughts on the undergraduate instructors. There was no specific question we asked them to answer: just how they felt the undergraduate instructors performed during the semester. Their responses support data gathered from a department-wide survey. One student responded that "instructors were neat and approachable," and another student said that "they made the material understandable and 


\begin{tabular}{|l|l|l|l|l|l|}
\hline & Sp2017 & Fa2017 & Sp2018 & Fa2018 & Sp2019 \\
\hline Applied & 58 & 54 & 58 & 83 & 62 \\
\hline Enrolled & 15 & 20 & 20 & 30 & 16 \\
\hline
\end{tabular}

Table 5: Application and enrollment counts across 5 semesters. We prioritized admissions toward first-year and transfer students who have little EE/CS background. Not all admitted students enrolled. Class size was capped at 30 due to space, resource, and instructor constraints.

approachable." Students also felt that the undergraduate instructors were dedicated, with one commenting that "I could feel that each lecturer cared about the topic they were talking about," and "I liked how the lecturers ... were passionate about their field of study." Although students in our survey were not asked to directly compare undergraduate instructors to graduate instructors, they still felt that undergraduates were approachable and passionate.

We emphasize that no faculty was involved in organizing and teaching the course. However, we relied on the faculty advisor for consulting and guidance on the direction of the course at the end of each semester, as well as for administrative matters such as course approval and grade submission. Intentionally low faculty involvement means the course requires little extra cost on the department and is not dependent on existing faculty commitments.

\subsection{Sustainability and Other Challenges}

The course has been offered for 5 semesters and is currently going into the sixth. Table 5 gives application and enrollment numbers across the previous 5 offerings. The class has been sustainable due to the honor society providing a large pool of qualified undergraduate students as well as extensive documentation on running and teaching the class that allows new course facilitators and instructors to quickly prepare for a new term.

For each iteration of the course a set of students is elected from our parent organization as facilitators of the course. These facilitators are responsible for handling the logistics of the course, and some facilitators also serve as instructors. As students typically do not join the honor society until their third year, we see high turnover rates in our potential instructor pool. In each iteration, at most half of the facilitators are returning facilitators, as many of them move to different parts of the parent organization or become inactive due to other commitments. This high turnover rate initially made it difficult to gather facilitators and instructors, but this issue became less acute as the program matured. In more recent offerings of the course, former students have become instructors, and they have provided invaluable insight into the usefulness of various portions of the course. However, we note at small institutions or ones without a large active EE/CS student organization, it may be difficult to find qualified, willing, and available undergraduates as instructors.

The largest source of non-personnel difficulty has been logistical tasks, as they frequently coincide with times when the undergraduate instructors are unavailable or away from campus. These tasks include room reservations, course enrollments, and outreach to transfer and incoming student programs. Enrollment in the course tends to be variable during the first few weeks of each term, during which students frequently adjust their schedules. These times are also frequently hectic for the undergraduate instructors, so a well-organized waitlist is necessary. Prospective students also need to be continuously updated on their position in the waitlist to aid their term planning.

Our primary method of keeping the course sustainable and selfsufficient despite high turnover rate in facilitators and instructors and minimal faculty involvement is to maintain extensive documentation on the following subjects:

(1) Course materials

(2) To-do lists for various times in the year

(3) Course infrastructure setup guides

(4) Departmental contacts for various bureaucratic functions

(5) Tasks for instructors and assistants

Additionally, this allows the instructors to focus on more relevant matters, such as updating course materials and rewriting activities. We note that these responsibilities, many of which which would typically fall to faculty in a regular course, are instead handled by the facilitators of the course. This offloading of work from the faculty advisor to the facilitators is vital to the long-term sustainability of the course, as it minimizes interruptions of the faculty member's primary responsibilities.

\section{CONCLUSION AND FUTURE WORK}

In summary, we present a first-term, low-overhead, undergraduatetaught, sustainable survey course to help new students make more informed choices toward their EE/CS education. This course is conducted with minimal faculty involvement, and it has been successful in increasing exposure and interest in less popular areas of electrical engineering and computer science.

Since most undergraduates remain in the school for only three to five years, in contrast to faculty members who may teach for upwards of forty, finding undergraduate instructors to teach the course is a constant challenge. In the future, we wish to scale our course to accommodate more students, establish a more robust instructor pipeline, and further investigate the long-term impact of our course on our students.

\section{ACKNOWLEDGMENTS}

The authors graciously thank the course organizers throughout the past 5 offerings: Chris Powers, Dalton Omens, Grace Park, Matthew Owen, Anastasia Scott, Nate Young, Justin Lin, Wenyuan Ma, Steven Lu, Aviral Pandey, and Mrunal Puram. The course was funded by Eta Kappa $\mathrm{Nu}$ - Mu Chapter and the Associated Students of the University of California Berkeley. The authors were partially supported by the National Science Foundation Graduate Research Fellowship Program under Grant No. DGE 1745016, and NSF Grants IIS-1247701, CCF-1563078. This material is based on research sponsored by DARPA under agreement number FA875014-2-0240, FA8750-17-2-0095 and by Air Force Research Laboratory (AFRL) and Defense Advanced Research Projects Agency (DARPA) under agreement number FA8650-18-2-7865. The U.S. Government is authorized to reproduce and distribute reprints for Governmental purposes notwithstanding any copyright notation thereon. The views and conclusions contained herein are those of the authors and should not be interpreted as necessarily representing the official policies or endorsements, either expressed or implied, of AFRL and DARPA or the U.S. Government. The opinions, findings, and conclusions or recommendations expressed are those of the author(s) and do not necessarily reflect the views of the National Science Foundation. 


\section{REFERENCES}

[1] James L Bess and John A Bilorusky. 1970. Curriculum hypocrisies: Studies of student-initiated courses. Higher Education Quarterly 24, 3 (1970), 291-309.

[2] Caitlin Cairncross, Tammy VanDeGrift, Sharon A Jones, and Zulema Naegele. 2015. Building an Academic Success Program for At-Risk Engineering Students. (2015).

[3] Mark A Casteel and K Robert Bridges. 2007. Goodbye lecture: A student-led seminar approach for teaching upper division courses. Teaching of Psychology 34, 2 (2007), 107-110.

[4] Hannah C Chapin, Benjamin L Wiggins, and Linda E Martin-Morris. 2014. Undergraduate science learners show comparable outcomes whether taught by undergraduate or graduate teaching assistants. Journal of College Science Teaching 44, 2 (2014), 90-99.

[5] Charles Dierbach, Blair Taylor, Harry Zhou, and Iliana Zimand. 2005. Experiences with a CS0 course targeted for CS1 success. In ACM SIGCSE Bulletin, Vol. 37. ACM, 317-320.

[6] Kelsey Dietz. 2015. Predicting Undergraduate Passions: An Analysis of Major Migration at Carnegie Mellon. (2015).

[7] Nadia Rahbek Dyrberg and Claus Michelsen. 2017. Mentoring First Year Study Groups-Benefits from the Mentors' Perspective. European fournal of Science and Mathematics Education 5, 1 (2017), 43-54.

[8] Christopher J Felege. 2018. The Long-Term Significance Of Working As An Undergraduate Teaching Assistant. University of North Dakota. Theses and Dissertations (2018).

[9] Channing R Ford, Emily B Wilkins, and James E Groccia. 2018. Students Engaged in Teaching. New Directions for Teaching and Learning 2018, 154 (2018), 33-43.

[10] Stewart Green, Nick Plant, and Courtney Chan. 2016. Student at Risk Identification and Remedial Action System for Improving Retention on Computer Science Programmes. New Directions in the Teaching of Physical Sciences 11 (2016).

[11] Eric Guizzo. 2008. The EE Gender Gap Is Widening. IEEE Spectrum (2008).

[12] Michael Hewner. 2014. How CS undergraduates make course choices. In Proceedings of the tenth annual conference on International computing education research. ACM, 115-122.

[13] Sharon A Jones and Caitlin Cairncross. 2016. Two-Tiered Summer Bridge Programming for At-Risk Engineering and Computer Science Students. (2016)

[14] Sandra Katz, David Allbritton, John Aronis, Christine Wilson, and Mary Lou Soffa. 2006. Gender, achievement, and persistence in an undergraduate computer science program. ACM SIGMIS Database 37, 4 (2006), 42-57.

[15] Päivi Kinnunen and Lauri Malmi. 2006. Why students drop out CS1 course?. In Proceedings of the second international workshop on Computing education research.
ACM, 97-108.

[16] Külli Kori, Margus Pedaste, and Olev Must. 2018. The Academic, Social, and Professional Integration Profiles of Information Technology Students. ACM Transactions on Computing Education (TOCE) 18, 4 (2018), 20

[17] Kathleen J Lehman, Linda J Sax, and Hilary B Zimmerman. 2017. Women planning to major in computer science: Who are they and what makes them unique? Computer Science Education 26, 4 (2017), 277-298.

[18] Ásrún Matthíasdóttir and Hrafn J Geirsson. 2011. The novice problem in computer science. In Proceedings of the 12th International Conference on Computer Systems and Technologies. ACM, 570-576.

[19] Elissa Meites, Joanna L Wagner, Michael KW Choy, and Mary Lake Polan. 2002. A student-initiated interactive course as a model for teaching reproductive health. American journal of obstetrics and gynecology 187, 3 (2002), S30-S33.

[20] Alexis Peschot, Chuang Qian, and Tsu-Jae Liu. 2015. Nanoelectromechanical Switches for Low-Power Digital Computing. Micromachines 6, 8 (Aug 2015), 1046âĂŞ1065. https://doi.org/10.3390/mi6081046

[21] Stephanie B Philipp. 2014. Strengthening STEM performance and persistence: Influence of undergraduate teaching assistants on entry-level STEM students. University of Louisville.

[22] Stephanie B Philipp, Thomas R Tretter, and Christine V Rich. 2016. Development of undergraduate teaching assistants as effective instructors in STEM courses. (2016).

[23] Bryan K Saville, Tracy E Zinn, and Marcus P Elliott. 2005. Interteaching versus traditional methods of instruction: A preliminary analysis. Teaching of Psychology 32, 3 (2005), 161-163.

[24] Bryan K Saville, Tracy E Zinn, Nancy A Neef, Renee Van Norman, and Summer J Ferreri. 2006. A comparison of interteaching and lecture in the college classroom. fournal of applied behavior analysis 39, 1 (2006), 49-61.

[25] Kelly A Schalk, J Randy McGinnis, Jeffrey R Harring, Amy Hendrickson, and Ann C Smith. 2009. The undergraduate teaching assistant experience offers opportunities similar to the undergraduate research experience. Fournal of Microbiology \& Biology Education: FMBE 10, 1 (2009), 32.

[26] Peter Sturmey, Samantha Dalfen, and Daniel M Fienup. 2015. Inter-teaching: systematic review. European fournal of Behavior Analysis 16, 1 (2015), 121-130.

[27] Janet M Weidert, Angela R Wendorf, Regan AR Gurung, and Tonya Filz. 2012. A survey of graduate and undergraduate teaching assistants. College Teaching 60, 3 (2012), 95-103.

[28] Lindsay B Wheeler, Jennifer L Maeng, Jennie L Chiu, and Randy L Bell. 2017. Do teaching assistants matter? Investigating relationships between teaching assistants and student outcomes in undergraduate science laboratory classes. Journal of Research in Science Teaching 54, 4 (2017), 463-492. 